\title{
Bioenergetics of Adaptation to a Salinity Transition in Euryhaline Teleost (Oreochromis mossambicus) Brain
}

\author{
Ching-Feng Weng, $* \nmid$ Chia-Chang Chiang, + Hong-Yi Gong, $\uparrow \S$ \\ Mark Hung-Chih Chen, $\dagger \nmid$ Wei-Tung Huang, $\dagger$ Ching-Yi Cheng, $\dagger$ and \\ JEN-LEIH WU††'\$ \\ *Institute of Biotechnology, National Dong Hwa University, Hualien, Taiwan, Republic of China; \\ †Institute of Zoology, Academia Sinica, Taipei, Taiwan 115, Republic of China; $\$$ Institute of \\ Fisheries Sciences, National Taiwan University, Taipei, Taiwan 100, Republic of China; and \\ $\S$ Graduate Institute of Life Sciences, National Defense Medical Center, Taipei, Taiwan 100, \\ Republic of China
}

Freshwater (FW) teleosts are capable of acclimating to seawater (SW) following such a transfer from FW. However, their osmoregulating mechanisms are still unclear, particularly those in the brain. The present study was conducted to examine acute changes that occur in brain $\mathrm{Na}^{+}-\mathrm{K}^{+}$-ATPase activity, creatine kinase (CK) activity, creatine, creatinine contents, and ATP levels of tilapia (Oreochromis mossambicus) in response to this transition. After transfer to SW (25 ppt), the $\mathrm{Na}^{+}-\mathrm{K}^{+}$-ATPase activity was maintained for $8 \mathrm{hr}$ at higher levels than that in FW. In contrast, in 35 ppt SW, $\mathrm{Na}^{+}-\mathrm{K}^{+}$-ATPase was maintained at a even higher level than in $\mathrm{FW}$ for the first $2 \mathrm{hr}$. Brain $\mathrm{Na}^{+}-\mathrm{K}^{+}-$ ATPase contents in both the 25 and 35 ppt SW groups were significantly elevated within 1 and $0.5 \mathrm{hr}$ after transfer from FW, respectively. Interestingly, brain CK activities and content (homodimer of the $B$ subunit [BB] form) in both the 25 and 35 ppt SW groups were significantly elevated within $1 \mathrm{hr}$ after transfer from FW. The ATP contents in 35 ppt SW increased abruptly within $0.5 \mathrm{hr}$, and then gradually decreased during the next $2 \mathrm{hr}$. Unlike the 35 ppt group that declined in ATP contents, the 25 ppt group leveled off within $24 \mathrm{hr}$. The elevations in CK activity and creatine levels after transfer from FW to SW imply that abrupt salinity changes alter phosphocreatine/CK ratio. Such changes are needed to satisfy the increases in the energetic requirement of the cotransport mechanisms mediating osmoregulation.

[Exp Biol Med Vol. 227(1):45-50, 2002]

Key words: brain $\mathrm{Na}^{+}-\mathrm{K}^{+}$-ATPase; creatine kinase; ATP; tilapia (Oreochromis mossambicus)

This work was supported by the Academia Sinica (Taiwan) under Grants 88 and 89 . ${ }^{1}$ To whom all requests for reprints should be addressed at Institute of Zoology, Academia Sinica, Taipei, Taiwan 115, Republic of China. E-mail: zojlwu@ ccvax.sinica.edu.tw

Received April 25, 2001

Accepted September 4, 2001.

$1535-3702 / 01 / 2271-0045 \$ 15.00$

Copyright $(9) 2002$ by the Society for Experimental Biology and Medicine reatine kinase (CK; EC 2.7.3.2) is used to transfer energy between phosphagens in the reversible reaction: ADP + phosphocreatine $\rightarrow$ ATP + creatine. $\mathrm{CK}$ exists as different isoforms comprised of either an alkaline homodimer of the $\mathrm{M}$ subunit (MM), an acidic homodimer of the $\mathrm{B}$ subunit (BB), or a heterodimer of the $\mathrm{M}$ and $B$ subunits (MB). These isoforms can be identified by differences in their electrophoretic mobility, tissue, subcellular distribution, and primary sequence $(1,2)$. Three different types of CK isoforms (brain, muscle, and mitochondria) exist in teleosts (reviewed in Refs. 3 and 4). Interestingly, trout spermatozoa $\mathrm{CK}$ activity is high (s-CK isozyme) (5), but a previous study showed that it was not present in gills (6).

The activity of plasma CK increases as a physiological stress response in big game fish after capture (7). Total CK activity significantly decreased by $20 \%$ in fish (Oreochromis mossambicus) brain after exposure to hypergravity for 7 days (8). On the other hand, CK levels are elevated in Atlantic salmon (Salmo salar) with severe degenerative myopathy (pancreas disease) $(9,10)$. Recently, an increase in CK activity was associated with developing skeletal muscle degeneration in sea bass, Dicentrarchus labrax (11). In addition, there is some evidence of seasonal fluctuations of $\mathrm{CK}$ in rainbow trout, Oncorhynchus mykiss (12); tissue variability in CK isozyme expression in rainbow trout, Oncorhynchus mykiss, and genetic variability of tissue CK between fish species including rainbow trout $(4,13)$. The presence of MM-type CK, BB-type CK, and mitochondrial CK was demonstrated with MM-type $\mathrm{CK}$ being predominant in Gillichthys mirabilis gills (14). Muscle-type CK is functionally coupled to $\mathrm{Na}^{+}-\mathrm{K}^{+}$-ATPase activity, in that ATP consumption is offset by CK-mediated dephosphorylation of creatine phosphate $(15,16)$. The $\mathrm{CK}$ of gills acts as an energy source to satisfy increases unenergetic requirements of gill $\mathrm{Na}^{+}-\mathrm{K}^{+}$-ATPase for osmoregulation after transfer 
from freshwater (FW) to seawater (SW; Weng CF, et al., unpublished data).

When a euryhaline teleost goes from hyperosmotic (SW) to hypo-osmotic (FW) media, it tends to gain water followed by loss of osmolytes and water in a regulatory volume response referred to as regulatory volume decrease. Alternatively, upon exposure to an increase in salinity, the initial effect is a loss in water followed by accumulation of osmolytes until the intracellular and extracellular osmolalities match one another. Therefore, regulatory volume responses are responsible for maintenance of a stable internal milieu, ionic regulation, and water balance. When tilapia were transferred directly to SW (35 ppt), they died within 4 hr. However, they survived after transfer to $25 \mathrm{ppt}$ SW (Weng CF, et al., unpublished data) (17). The organs involved in osmoregulation in teleosts include the opercular membrane, gill, gut, kidney, and urinary bladder. The gill is the primary organ that responds to the critical problem of salinity changes in teleostean fish; however, it is not known whether other vital organs such as the brain also play a functional role (ion transport and water balance) in adapting to transfer from FW to SW. Previously, it was determined that $\mathrm{CK}$ is needed during critical phases of brain development in the cichlid fish Oreochromis mossambicus and the clawed toad Xenopus laevis. It is very sensitive during this period to changes in environmental conditions (e.g., gravity) (8).

In the current study, we determined which type of CK is regulated by salinity. The results showed that gill CK activity in tilapia (O. mossambicus) was characterized and altered by salinity, directly or indirectly, especially muscletype CK (Weng CF, et al., unpublished data). Furthermore, we characterized changes in brain $\mathrm{Na}^{+}-\mathrm{K}^{+}$-ATPase activity, ATP levels, creatine and creatinine contents, and CK after short-term transfer from FW to 25 and $35 \mathrm{ppt}$ SW in the present study.

\section{Materials and Methods}

Animals. Tilapia (O. mossambicus) were originally obtained from the Tainan Fish Culture Station of the Taiwan Fisheries Research Institute and were maintained in a freshwater recirculating tank at $25^{\circ}-28^{\circ} \mathrm{C}$ at the Institute of Zoology, Academia Sinica (Taipei, Taiwan). They varied from 5 to $7 \mathrm{~cm}$ in total length and weighed from 2.5 to $4.0 \mathrm{~g}$. Tilapia were transferred from $\mathrm{FW}$ to 25 or $35 \mathrm{ppt} \mathrm{SW}$ for various times $(0.5,1,1.5,2,4,8,16$, and $24 \mathrm{hr}, n=6-8$, at each time point). Fish were anesthetized on ice and were sacrificed immediately. The brain was removed and weighed followed by homogenization with a motorized Teflon pestle at $1000 \mathrm{rpm}$ for $2 \mathrm{~min}$ on ice in a solution containing $100 \mathrm{mM}$ imidazole- $\mathrm{HCl}$ buffer, $\mathrm{pH} 7.0,5 \mathrm{mM}$ $\mathrm{Na}_{2}$ EDTA, $200 \mathrm{mM}$ sucrose, and $0.1 \%$ sodium deoxycholate. After centrifugation $\left(12,000 \mathrm{rpm}\right.$ for $30 \mathrm{~min}$ at $\left.4^{\circ} \mathrm{C}\right)$, the supernatant was kept at $-70^{\circ} \mathrm{C}$ until assay. Total protein was determined with a Bio-Rad protein assay kit (Bio-Rad,
Hercules, CA) and bovine serum albumin was used as a standard (Fraction V., Sigma, St. Louis, MO).

CK Activity. Brain CK activity was measured using a commercial kit (Sigma) as per enclosed instructions, with minor modifications (small volume). The reactions are ADP + phosphocreatine $\rightarrow$ ATP + creatine, and creatine + $\alpha$-naphthol + diacetyl $\rightarrow$ colored complex. Diluted samples $(0.2 \mathrm{ml})$ were mixed with $0.5 \mathrm{ml}$ of phosphocreatine solution $(0.2 \mathrm{ml})$. ADP-glutathione solution (start reaction) was added to each tube and they were mixed vigorously and incubated for $30 \mathrm{~min}$ at $37^{\circ} \mathrm{C}$. Afterwards, $20 \mu \mathrm{l}$ of $p$ hydroxymercuribenzoate was added to stop the reaction, and then $100 \mu \mathrm{l}$ of $\alpha$-naphthol solution, $100 \mu \mathrm{l}$ of diacetyl solution, $700 \mu \mathrm{l}$ of $\mathrm{mH}_{2} \mathrm{O}$ or double distilled water (D.D.W.) were added and mixed well. After incubation at $37^{\circ} \mathrm{C}$ for 20 $\mathrm{min}$, the tubes were centrifuged at $3500 \mathrm{rpm}$ for $5 \mathrm{~min}$. The absorbance of the supernatant was measured at $520 \mathrm{~nm}$. The CK activity of unknown samples was calculated by comparing them with creatine standards. The data are expressed in micromoles of creatine released per milligram of protein.

$\mathrm{Na}^{+}-\mathrm{K}^{+}$-ATPase Activity. The measurement of brain $\mathrm{Na}^{+}-\mathrm{K}^{+}$-ATPase activity was determined by the rate of Pi formation. Briefly, a sample (80-100 $\mu \mathrm{g}$ of total protein) was added to a reaction buffer that contained (in millimoles): 100 imidazole- $\mathrm{HCl}$ buffer, $\mathrm{pH} 7.6,125 \mathrm{NaCl}, 75$ $\mathrm{KCl}, 7.5 \mathrm{MgCl}_{2}$, and $5 \mathrm{Na}_{2}$ ATP. After incubation at $37^{\circ} \mathrm{C}$ for $30 \mathrm{~min}$, the samples were placed on ice and $30 \%$ tricholoroacetic acid (TCA) was added to stop the reaction. The vials were centrifuged at $4000 \mathrm{rpm}$ at $4^{\circ} \mathrm{C}$ for $10 \mathrm{~min}$; the supernatant and the phosphate standards were added with $2.5 \%$ acid molybdate solution, $10 \%$ SDS, and $0.025 \%$ $\mathrm{NaHSO}_{3}\left(\mathrm{Na}_{2} \mathrm{SO}_{3}, 1\right.$-amino-2-naphthol-4-sulfomic acid). After incubation at $20^{\circ} \mathrm{C}$ for $30 \mathrm{~min}$. Pi production was measured at $700 \mathrm{~nm}$ following the method of Peterson (18). The $\mathrm{Na}^{+}-\mathrm{K}^{+}$-ATPase activity was defined as the difference in the inorganic phosphate liberated in the presence and absence of $0.5 \mathrm{mM}$ ouabain. Data are expressed in micromoles of inorganic phosphate released per milligram of protein per hour.

ATP. The ATP level was measured as per instructions provided with a commercial kit (Sigma). The reactions are: $\mathrm{ATP}+3$-phosphoglycerate ${ }^{\mathrm{PGK}} \rightarrow \mathrm{ADP}+1,3$-diphosphoglycerate, and 1,3-diphosphoglycerate $+\mathrm{NADH}^{\mathrm{GAPD}} \rightarrow$ glyceradehyde-3-P + NAD + P. The amount of ATP in a $10-\mu l$ sample was determined by the decrease in absorbance at $340 \mathrm{~nm}$ (Spectophotometer, Hitachi, Japan) that occurs when NADH is oxidized to NAD. The data are expressed as micromoles of ATP released per milligram of protein.

Creatine. The creatine content was measured spectrophotometrically using a protocol described in a commercial kit (Sigma). The reaction is: creatine $+\alpha$-naphthol + diacetyl $\rightarrow \rightarrow$ colored complex. The absorbance of the supernatant was measured at $520 \mathrm{~nm}$. The creatine content of unknown samples was calculated by comparison with the creatine standard. The data are expressed in micromoles of creatine released per milligram of protein. 
Creatinine. Creatinine was measured as per instructions provided with a commercial kit (Sigma). The absorbances of the standard and test samples were read at $500 \mathrm{~nm}$ as an initial value. Thereafter, $0.1 \mathrm{ml}$ of acid reagent (a mixture of sulfuric acid and acetic acid) was added and mixed. The mixture was again incubated at room temperature for $5 \mathrm{~min}$. The final value of absorbance was read. The absorbance of the test sample is equal to the initial value minus the final value. The creatinine content of test samples was calculated by comparison with the creatinine standard.

Western Blotting. Brain homogenate (total protein $100 \mu \mathrm{g}$ ) was mixed with an equal volume of $2 \times$ electrophoresis sample buffer containing 1,4-dithiothreithol (DTT). The proteins were separated by electrophoresis on a $4 \%-$ $12 \%$ gradient polyacrylamide slab gel (NuPAGE, Novex, CA) and were electrophoretically transferred to a PVDF membrane (Amersham Life Science, Buckinghamshire, UK). The blots were incubated overnight in 3\% NET buffer $(0.25 \%$ gelatin, $50 \mathrm{mM} \mathrm{NaCl}, 50 \mathrm{mM}$ Tris- $\mathrm{HCl}, 5 \mathrm{mM}$ EDTA, pH 7.5, and 0.05\% Tween-20) and were washed three times in PBST buffer $(0.01 \mathrm{M}$ phosphate, $0.09 \% \mathrm{NaCl}$, $\mathrm{pH} 7.5$, and $0.05 \%$ Tween-20). Membranes were incubated for $2 \mathrm{hr}$ with mouse anti-chicken $\mathrm{Na}^{+}-\mathrm{K}^{+}$-ATPase $\alpha$ subunit monoclonal antibody in a 1:2000 dilution. The membranes were stripped and reprobed with (1:2000) for mouse antihuman muscle form (MM) CK monoclonal antibody or (1:1000) for rabbit anti-human brain form (BB) CK polyclonal antibody. After washing three times with PBST, immunoreactive proteins were visualized using an enhanced chemiluminescent (ECL) system (Pierce, Rockford, IL) according to the instructions supplied by the manufacturer. The differences in the band intensity of FW and SW were compared using densitometry (Personal Densitometer SI, Molecular Dynamics, Sunnyvale, CA).

Statistics. All data are expressed as the mean \pm SEM. Differences among the groups were determined by one-way analysis of variance (ANOVA), and means among them were compared with $\mathrm{FW}$ values by the student $t$ test. $P$ values $<0.05$ were chosen to be significant. The relationships between $\mathrm{CK}$ and $\mathrm{Na}^{+}-\mathrm{K}^{+}$-ATPase activity were tested by correlation analysis.

\section{Results}

Tilapia died $4 \mathrm{hr}$ after transfer from FW to $35 \mathrm{ppt} \mathrm{SW}$, which is in agreement with a previous report on tilapia (17). In the present study, we measured the short-term effects of this transfer on brain $\mathrm{Na}^{+}-\mathrm{K}^{+}$-ATPase activity, ATP levels, $\mathrm{CK}$ activity, and creatine and creatinine contents.

$\mathrm{Na}^{+}-\mathrm{K}^{+}$-ATPase. Brain $\mathrm{Na}^{+}-\mathrm{K}^{+}$-ATPase activity in fish transferred to SW (35 ppt) increased within $0.5 \mathrm{hr}$ and then dropped shortly thereafter to a level higher than that in FW. After transfer from FW to 25 ppt SW, brain $\mathrm{Na}^{+}-\mathrm{K}^{+}-$ ATPase activity of fish increased within $1 \mathrm{hr}$ and then remained elevated for the next $24 \mathrm{hr}$ (Fig. 1). Western blotting data showed that brain $\mathrm{Na}^{+}-\mathrm{K}^{+}$-ATPase in $\mathrm{FW}$ was lower than that in SW. On the other hand, transfer to SW (35 ppt)

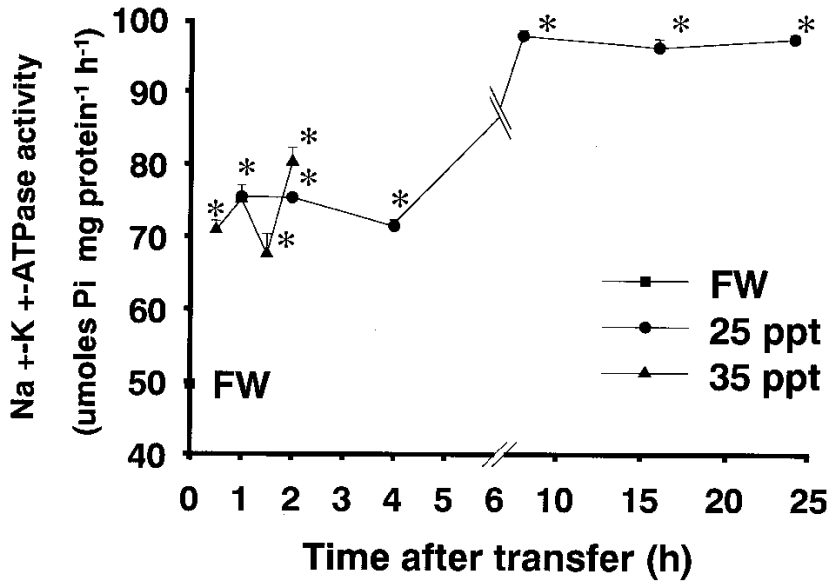

Figure 1. Acute responses of $\mathrm{Na}^{+}-\mathrm{K}^{+}$-ATPase activity in tilapia brain at various times after transfer from $\mathrm{FW}$ to 25 or $35 \mathrm{ppt} \mathrm{SW}$. The data are expressed as the mean \pm SEM $(n=6$, two independent experiments). An asterisk indicates a significant difference $(P<0.05)$ between the FW control and the 25 or 35 ppt SW groups.

caused $\mathrm{Na}^{+}-\mathrm{K}^{+}$-ATPase to increase within $0.5 \mathrm{hr}$ to a higher level, and then dropped shortly to a level lower than that in FW. In 25 ppt SW, the $\mathrm{Na}^{+}-\mathrm{K}^{+}$-ATPase expression increased within $1 \mathrm{hr}$ after transfer. Interestingly, brain $\mathrm{Na}^{+}-$ $\mathrm{K}^{+}$-ATPase reached a higher level within $2 \mathrm{hr}$ after transfer and was then maintained at higher levels for the next $24 \mathrm{hr}$ (Fig. 2, A and B).

CK. Brain CK activity in fish transferred to SW (35 ppt) increased within $0.5 \mathrm{hr}$ and then elevated to a level

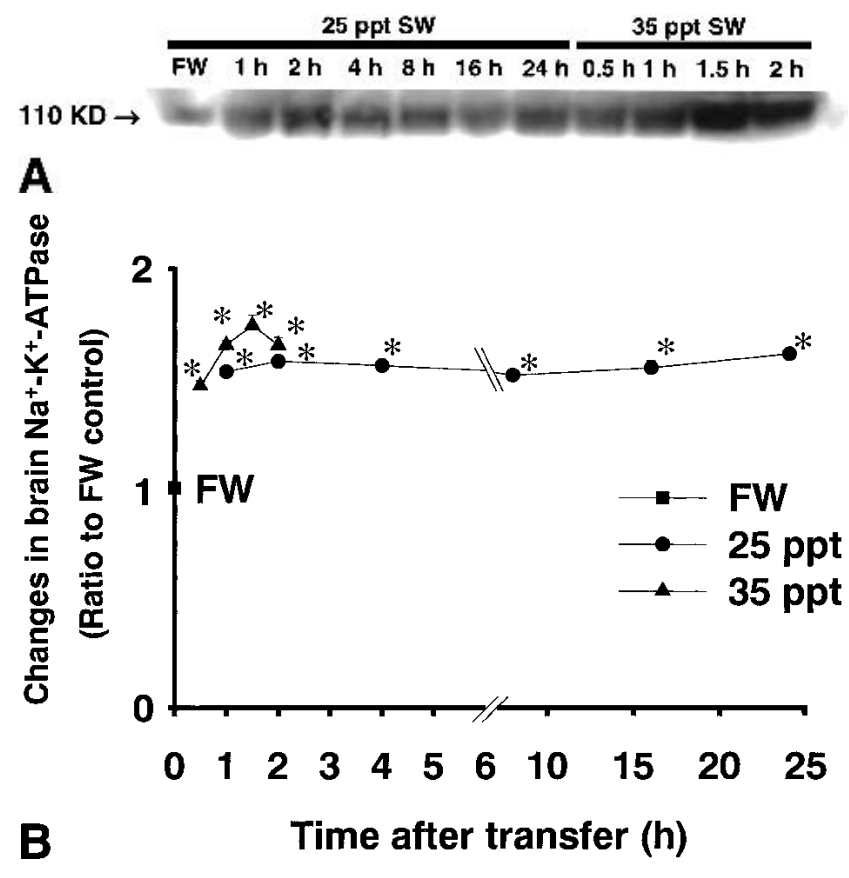

Figure 2. Acute responses of tilapia brain. (A) Western blot of $\mathrm{Na}^{+}$$\mathrm{K}^{+}$-ATPase alpha subunit and (B) changes of $\mathrm{Na}^{+}-\mathrm{K}^{+}$-ATPase protein (Western blot) in tilapia brain at various times after transfer from FW to 25 or $35 \mathrm{ppt} \mathrm{SW}$. The data are expressed as the mean \pm SEM ( $n=6$, two independent experiments). An asterisk indicates a significant difference $(P<0.05)$ between the FW control (the value as 1 , intensity is $38.2 \pm 8.7$ ) and the 25 or 35 ppt SW groups. 
higher than that in FW. Similarly, after transfer from FW to 25 ppt SW, brain CK activity increased 5-fold within $1 \mathrm{hr}$ and remained stable for $8 \mathrm{hr}$. Its activity declined after $8 \mathrm{hr}$ as it did in FW (Fig. 3). In addition, transfer to SW (35 ppt) caused CK (BB form) content to increase gradually within $1.5 \mathrm{hr}$ to a higher level, and then it dropped to a level lower (at $2 \mathrm{hr}$ ) than that in FW. In 25 ppt SW, the CK (BB form) content increased within $1 \mathrm{hr}$ after transfer and was then maintained at higher levels for the next $8 \mathrm{hr}$. Afterward, it dropped to the same level as in FW at $16 \mathrm{hr}$ and then increased to a higher level at $24 \mathrm{hr}$ (Fig. 4, A and B). No CK (MM form) was detected in brain (data not shown). Correlation analysis indicated that there is no significant relationship between $\mathrm{CK}$ activity and $\mathrm{Na}^{+}-\mathrm{K}^{+}$-ATPase activity $\left(\mathrm{r}^{2}\right.$ $=0.28$ ) following transfer from $\mathrm{FW}$ to $\mathrm{SW}$.

ATP. The brain ATP level dramatically decreased after transfer to $25 \mathrm{ppt}$ for $2 \mathrm{hr}$ or $35 \mathrm{ppt}$ for $1 \mathrm{hr}$, respectively. Compared with the FW level, the ATP levels in both the 25 and 35 ppt SW groups were lower than that in the FW group (Fig. 5).

Creatine and Creatinine. Alterations in brain creatine content paralleled changes in CK activity after transfer from FW to SW (Fig. 6). After transfer to 25 ppt SW, the creatine levels were elevated within $1 \mathrm{hr}$ when compared with that of the FW group. Thereafter, the activity declined after $8 \mathrm{hr}$ in both the 25 and 35 ppt SW groups. In contrast, the creatinine content was lower than creatine and declined after the transition compared with the FW group (Fig. 7).

\section{Discussion}

$\mathrm{Na}^{+}-\mathrm{K}^{+}$-ATPase activity in tilapia brain after transfer from $\mathrm{FW}$ to $\mathrm{SW}$ (25 ppt) was maintained at higher levels for $24 \mathrm{hr}$ compared with those in FW. In addition, brain $\mathrm{Na}^{+}$$\mathrm{K}^{+}$-ATPase activity of the $35 \mathrm{ppt} \mathrm{SW}$ group reached a higher level within $1 \mathrm{hr}$ than did that of fish in $25 \mathrm{ppt} \mathrm{SW}$.

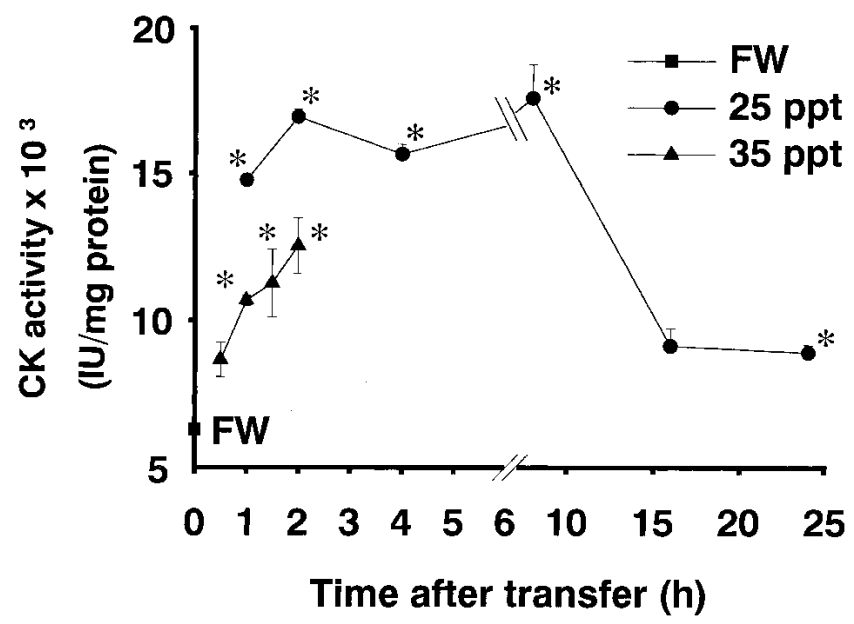

Figure 3. Acute responses of creatine kinase activity in tilapia brain at various times after transfer from FW to 25 or 35 ppt SW. The data are expressed as the mean $\pm \operatorname{SEM}(n=6$, two independent experiments). An asterisk indicates a significant difference $(P<0.05)$ between the FW control and the 25 or 35 ppt SW groups.

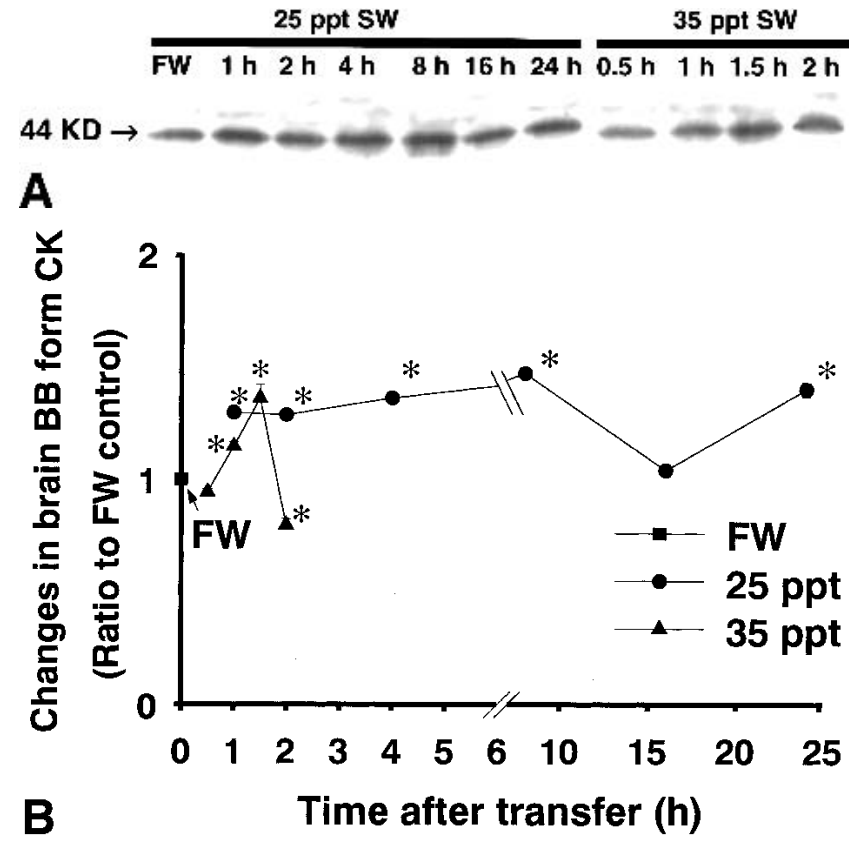

Figure 4. Acute responses of tilapia brain. (A) Western blot of braintype CK (BB form) and (B) alterations of brain-type CK (BB form, Western blot) in tilapia brain at various times after transfer from FW to 25 or 35 ppt SW. The data are expressed as the mean \pm SEM $(n$ $=6$, two independent experiments). An asterisk indicates a significant difference $(P<0.05)$ between the FW control (the value as 1 , intensity is $13.6 \pm 2.7$ ) and the 25 or 35 ppt SW groups.

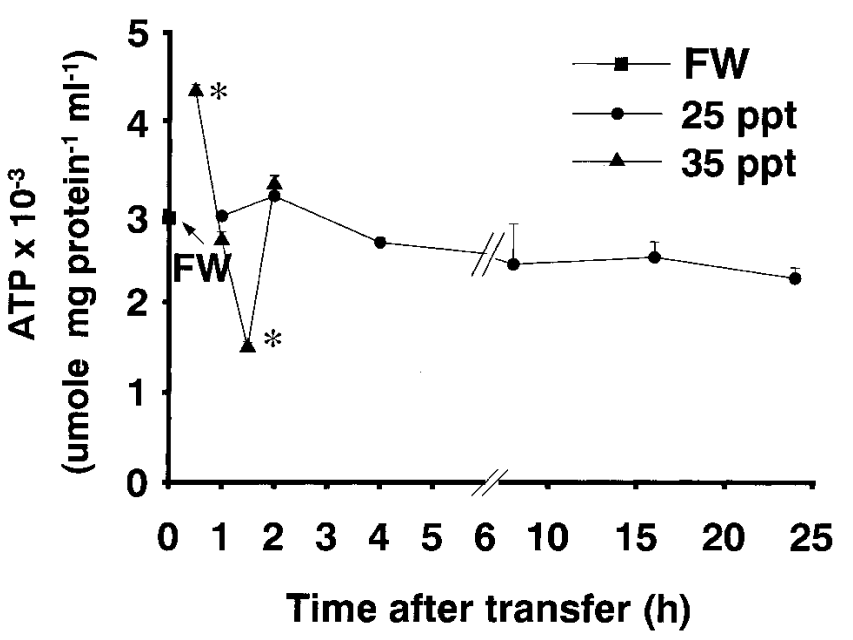

Figure 5. Acute response of tilapia brain ATP at various times after transfer from FW to SW (25 or $35 \mathrm{ppt}$ ). The data are expressed as the mean \pm SEM ( $n=6$, two independent experiments). An asterisk indicates a significant difference $(P<0.05)$ between the FW control and the 25 or 35 ppt SW groups.

Brain $\mathrm{Na}^{+}-\mathrm{K}^{+}$-ATPase contents in both the 25 and $35 \mathrm{ppt}$ SW groups were significantly elevated within 1 and $0.5 \mathrm{hr}$ after transfer from FW, respectively. Interestingly, brain $\mathrm{CK}$ activities and content (BB form) in both the 25 and $35 \mathrm{ppt}$ SW groups were significantly elevated within $1 \mathrm{hr}$ after transfer from FW. ATP levels in 35 ppt SW increased abruptly within $0.5 \mathrm{hr}$, but then gradually decreased within $2 \mathrm{hr}$ after transfer. In contrast, the ATP content remained at a constant level for $24 \mathrm{hr}$ after transfer from $\mathrm{FW}$ to $25 \mathrm{ppt}$ 


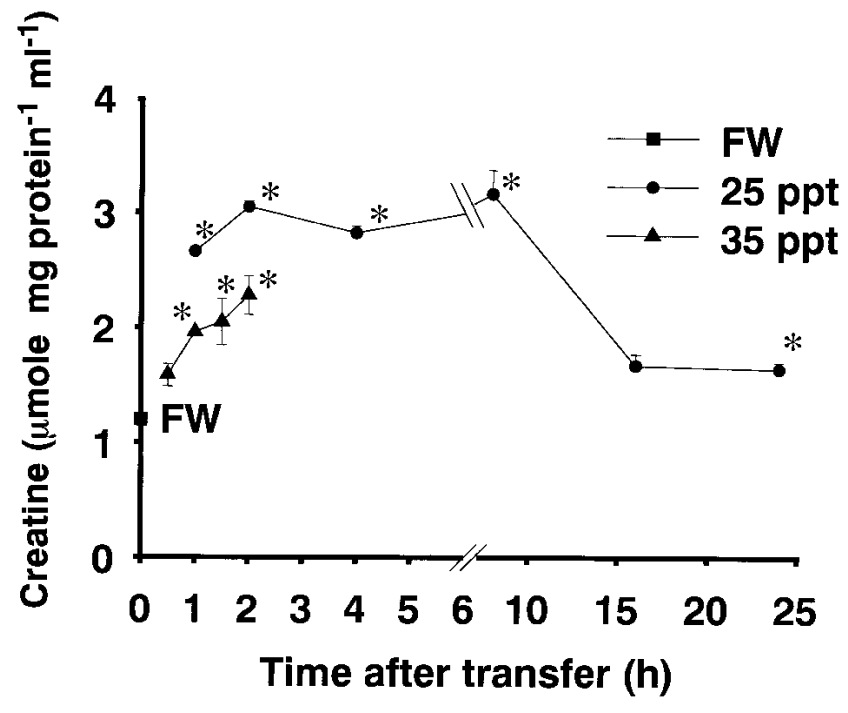

Figure 6. Acute response of tilapia brain creatine at various times after transfer from FW to SW (25 or $35 \mathrm{ppt}$ ). The data are expressed as the mean \pm SEM ( $n=6$, two independent experiments). An asterisk indicates a significant difference $(P<0.05)$ between the FW control and the 25 or 35 ppt SW groups.

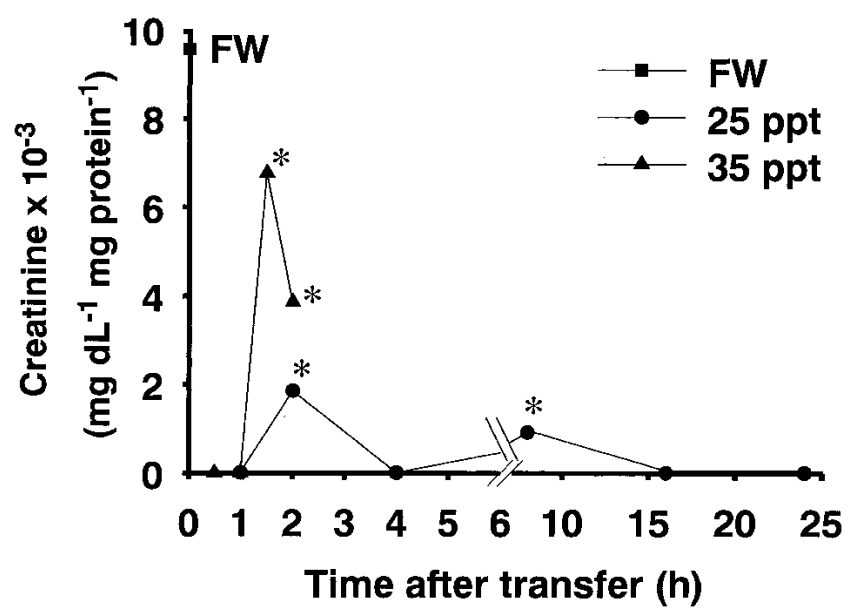

Figure 7. Acute response of tilapia brain creatinine at various times after transfer from FW to SW (25 or $35 \mathrm{ppt}$ ). The data are expressed as the mean \pm SEM ( $n=6$, two independent experiments). An asterisk indicates a significant difference $(P<0.05)$ between the FW control and the 25 or 35 ppt SW groups.

SW, but this level was lower compared with the FW group. This lack of correlation suggests that ATP levels did not fall enough to affect $\mathrm{Na}^{+}-\mathrm{K}^{+}$-ATPase activity. This is tenable because the apparent $\mathrm{K}_{\mathrm{m}}$ for ATP of the Na:K pump is far lower than cellular Km ATP content. Therefore, the energy buffering function of $\mathrm{CK}$ was not critical to the maintenance of pump activity during exposure to $25 \mathrm{ppt}$.

In teleosts, alterations of the environment (e.g., water $\mathrm{pH}$, salinity, or heavy metal pollution) cause physiological responses such as changes in hormone concentrations (growth hormone, prolactin, cortisol, etc.); changes in plasma ion levels (e.g., $\mathrm{Na}^{+}$, and $\mathrm{Cl}^{-}, \mathrm{K}^{+}$) and osmolarity; glucose and oxygen consumption rates (19); and water drinking activity (20). Fish expend large amounts of energy, particularly in the gill, intestine, kidney, and brain, to compensate for these salinity changes. The energetics of these additive responses to changes in salinity is not yet fully understood. In general, the function of phosphocreatine in excitable cells (particularly muscle and heart) is to provide an acute energy source in both aerobic and anaerobic metabolism. Phosphocreatine/CK is present in some excitable tissues (Narcine brasiliensis electric organ) (21) and nonexcitable tissues (Gillichthys mirabilis gills; Oreochromis mossambicus gills; and Squalus acanthias rectal gland) (14, 22; Weng CF, et al., unpublished data) with large fluctuating energy demands. Moreover, the normal demands placed upon $\mathrm{Na}^{+}-\mathrm{K}^{+}$-ATPase during the process of generation of electrical currents require large and rapid changes in activity of CK in the electric organ (22). Recently, it was found that CK provides an energy source for ion transport $\left(\mathrm{Na}^{+}-\mathrm{K}^{+}-\right.$ ATPase) in G. mirabilis gill based on the effects of iodoacetamide (14). This implies that changes in CK activity may be a good indicator of increases in energy conversion after transfer from FW to SW.

Brain CK activity in the 35 ppt SW group was lower than in the 25 ppt SW group. Similarly, the $\mathrm{Na}^{+}-\mathrm{K}^{+}$-ATPase activity of gills in $35 \mathrm{ppt}$ SW fish was lower than that in the 25 ppt SW group. Therefore, the change in brain CK activity was insufficient to meet the energy demand increase during the critical phase after transfer to $35 \mathrm{ppt}$ SW. This appears to be the case since the ATP levels fell following transfer from FW to either 25 or 35 ppt. Nevertheless, fish can adapt to 25 ppt. This finding is in agreement with previous reports $(17,23)$. In a previous study (Weng CF, et al., unpublished data ), CK activity of tilapia gill changed in concert with alterations in salinity ( $25 \mathrm{ppt} \mathrm{SW}$ ), suggesting that initially, adaptation is dependent on increases in CK activity. Another indication of this association is that there was a positive correlation between increases in CK and $\mathrm{Na}^{+}-\mathrm{K}^{+}$-ATPase activity in tilapia gill. In the current study, increases in brain $\mathrm{Na}^{+}-\mathrm{K}^{+}$-ATPase reflect the need to increase ion transport rates after salinity increments even though the increases in $\mathrm{Na}^{+}-\mathrm{K}^{+}$-ATPase and CK activity are not related to one another; increases in CK activity contribute to the energetic requirement for survival in $25 \mathrm{ppt}$.

Changes in CK activity are needed during the critical phases of brain development, and changes in CK activity occurs during exposure to environmental stress in channel catfish (24). The marine fish, Red seabream (Pagrus major) and Pacific mackerel (Scomber japonicus) possess less thermostable muscle CK than do carp (Cyprinus carpio) (25). We found that increases in tilapia brain CK content (BB form) also occurred following transfer to $25 \mathrm{ppt}$, which further shows that this transition is a common feature needed for adaptation to an environmental challenge. Recently, three muscle CK isoforms of carp (C. carpio) were cloned and characterized (26). They proposed that increases in a specific isoform expression might be linked to acclimation during an increase in environmental temperature. In a preliminary study, two different isoforms of MM-CK in 
gills one expressed during SW transfer, which have been cloned and sequenced (Kong, et al.,). Our current interest is to determine in tilapia brain whether the BB-CK isoform is specifically upregulated in response to such a transition.

Creatine is converted into creatinine in muscle and kidney. The urine creatinine level is a functional indicator of kidney clearance. The brain creatinine level of fish in FW was higher than that of fish in SW (25 or $35 \mathrm{ppt}$ ) in this study. The brain creatine level increased after SW, which is consistent with a higher ATP level at $0.5 \mathrm{hr}$ after transfer to 35 ppt because creatine phosphate concentrations decreased. This association implies a tight coupling of the ATP/ADP reaction to the creatine phosphate/Creatine reaction (27). There is more creatine available in SW adapted fish than the FW counterpart for metabolism to creatinine since more creatine phosphate is dephosphorylated to creatine due to increases in CK activity. Taken together, creatine and creatinine levels in brain as in serum might contribute to meeting the increased energetic cost of increases in ion transport activity that are needed for cellular homeostasis in response to an increase in salinity.

1. Villarreal LG, Ma TS, Kerner SA, Roberts R, Perryman MB. Human creatine kinase: isolation and sequence analysis of cDNA clones for the B subunit, development of subunit specific probes and determination of gene copy number. Biochem Biophys Res Commun 144:11161127, 1987.

2. Perryman MB, Kerner SA, Bohlmeyer TJ, Roberts R. Isolation and sequence analysis of a full-length cDNA for human $\mathrm{M}$ creatine kinase. Biochem Biophys Res Commun 140:981-989, 1986.

3. Coppes ZL, Vecchi SD, Ferreira E, Hirschhorn M. Multilocus isozyme systems in fish. Comp Biochem Physiol 96B:11-13, 1990.

4. Rottiers DV, Redell LA, Booke HE, Amaral S. Differences in stocks of American shad from the Columbia and Delaware rivers. Trans Am Fish Soc 121:132-136, 1992.

5. Saudrais C, Garber AT, McKay DJ, Dixon GH, Loir M. Creatine kinase in trout male germ cells: purification, gene expression, and localization in the testis. Mol Reprod Dev 44:433-442, 1996.

6. Garber AT, Winkfein RJ, Dixon GH. A novel creatine kinase cDNA whose transcript shows enhanced testicular expression. Biochem Biophys Acta 1087:256-258, 1990.

7. Wells RM, McIntyre RH, Morgan AK, Davie PS. Physiological stress responses in big gamefish after capture: observations on plasma chemistry and blood factors. Comp Biochem Physiol 84A:565-571, 1986.

8. Slenzka K, Appel R, Rahmann H. Brain creatine kinase activity during ontogeny of the cichlid fish Oreochromis mossambicus and the clawed toad Xenopus laevis, influence of gravity? Neurochem Int 22:405-411, 1993.

9. Ferguson HW, Rice DA, Lynas JK. Clinical pathology of myodegeneration (pancreas disease) in Atlantic salmon (Salmo salar). Vet Rec 119:297-299, 1986.

10. Rodger HD, Murphy TM, Drinan EM, Rice DA. Acute skeletal my- opathy in farmed Atlantic salmon, Salmo salar. Dis Aquatic Organisms 12:17-23, 1991.

11. Meassager JL, Stephan G, Quentel C, Baudin-Laurencin F. Effects of dietary oxidized fish oil and antioxidant deficiency on histopathology, haematology, tissue and plasma biochemistry, Dicentrarchus labrax. Aquatic Living Resources 5:205-214, 1992.

12. Bucher F. Organ patterns and natural fluctuations of blood enzymes of rainbow trout, Salmo gairdneri Rich. Comp Biochem Physiol 96B:795-800, 1990.

13. Paaver TK. Electrophoretic variability of proteins and genetic features of breed groups and stocks of rainbow trout, Salmo gairdneri, reared in the USSR. Voprosy Ikhtiologii 28:595-603, 1988.

14. Kultz D, Somero GN. Ion transport in gill of the euryhaline fish Gillichthys mirabilis is facilitated by a phosphocreatine circuit. Am J Physiol 268:R1003-R1012, 1995.

15. Saks VA, Lipina NV, Sharov VG, Sminov VN, Chazov EI, Grosse R. The localization of the MM isoenzyme of creatine phosphokinase on the surface membrane of myocardial cells and its functional coupling to ouabain-inhibited $\mathrm{Na}^{+}-\mathrm{K}^{+}$-ATPase. Biochem Biophys Acta 465:550-558, 1977

16. Saks VA, Belikova YO, Kuznetsov AV. In vivo regulation of mitochondrial respiration in cardiomyocytes: specfic restriction for intracellular diffusion of ATP. Biochem Biophys Acta 1074:302-311, 1991.

17. Hwang PP, Sun CM, Wu SM. Changes of plasma osmolality, chloride concentration and gill $\mathrm{Na}^{+}-\mathrm{K}^{+}$-ATPase activity in tilapia (Oreochromis mossambicus) during seawater acclimation. Mar Biol 100:295-299, 1989.

18. Peterson GL. A simplified method for analysis of inorganic phosphate in the presence of interfering substances. Anal Biochem 84:164-172, 1978.

19. McCormick SD. In Hoar WS, Randall DJ, Farrell AP, Eds. Fish Physiology: Cellular and Molecular Approaches to Fish Ionic Regulation. San Francisco: Academic Press, Vol. 14:285-315, 1995.

20. Lin LY, Weng CF, Hwang PP. Effects of cortisol on water balance in SW transferred tilapia (Oreochromis mossambicus) larvae. Physiol Biochem Zool 73:283-289, 2000

21. Blum H, Balschi JA, Johnson RG Jr. Coupled in vivo activity of creatine phosphokinase and the membrane-bound $\mathrm{Na}^{+}-\mathrm{K}^{+}$-ATPase in the resting and stimulated electric organ of the electric fish Narcine brasiliensis. J Biol Chem 266:10254-10259, 1991.

22. Friedman DL, Robert R. Purification and localization of brain-type creatine kinase in sodium chloride transporting epithelia of the spiny dogfish, Squalus acanthias. J Biol Chem 267:4270-4276, 1992.

23. Hwang PP. Tolerance and ultrastructural responses of branchial chloride cells to salinity changes in the euryhaline teleost Oreochromis mossambicus. Mar Biol 94:643-649, 1987.

24. Ellsaesser CF, Clem LW. Blood serum chemistry measurements of normal and acutely stressed channel catfish. Comp Biochem Physiol 88A:589-594, 1987.

25. Nakagawa T, Nagayama F. Enzymatic properties of fish muscle creatine kinase. Comp Biochem Physiol 98B:349-354, 1991.

26. Sun HW, Hui CH, Wu JL. Cloning, characterization, and expression in Escherichia coli of three creatine kinase muscle isoenzyme cDNAs from carp striated muscle. J Biol Chem 273:33774-33780, 1998.

27. Moon TW, Altringham JD, Johnston IA. Energetics and power output of isolated fish fast muscle fibres performing oscillatory work. J Exp Biol 158:261-273, 1991. 